\title{
The Agreeableness Type of Personality and the Basic Personal Values
}

Fitore Bajrami Abdi, PhD. Cand

Department of Psychology, Faculty of Philosophy, University of Tetova, Republic of Macedonia

\begin{abstract}
The goal of this study is to discover the relationship between the agreeableness type of personality and the basic personal values, analyzed through non-experimental methodology and quantitative approach. The sample of this study is the Albanian high school seniors in Skopje, Republic of Macedonia which consists of 479 subjects, randomly selected from the total sample specified. The subjects' willingness to participate in the survey and their anonymity was respected by following all ethical norms. The results of correlative statistics show that there is association between the agreeableness type and all basic personal values, while the comparative statistics indicate statistically significant differences between the basic personal values related to the agreeableness type of personality and the highest mean score was reached by the value universalism. The Eta square agreeableness type of personality results showed a relatively low effect on the values stimulation as well as hedonism.
\end{abstract}

Keywords: personality, agreeableness type, basic personal values.

\section{Introduction}

The goal of this study is to discover the relationship between the agreeableness type of personality and the basic personal values, variables that belong to organizational psychology and the theory of personality.

Agreeableness is a personality trait that holds people to be accommodating and help (Burch and Anderson, 2008) them solve issues by creating win-win situation by their flexible attitude (Cattell and Mead, 2008). The notion value refers to beliefs on which situations or actions are desirable. Basic personal values are treated based on Salom Shwartz theory i.e. the Theory of basic values $(1994,2012)$. Shwartz sees values as consistent standards based on which we value everything else, including the appropriateness of norms, attitudes, traits or virtues that might be suggested to us. The values included in this study are: conformity, tradition, benevolence, universalism, self-direction, stimulation, hedonism, achievement, power and security. Guth et.al (1965) stresses that: "Values are not only closely related to personality, they are part of it, and serve as a guiding system by personality when facing choices and alternatives, values form a very consistent personality trait of an individual, especially if some values are clearly dominated by the others".

It is the first time in the Republic of Macedonia that statistical data related to the abovementioned variables are presented. Therefore, these results will open one more page for the organizational psychology and researchers who will examine these variables in the Republic of Macedonia.

\subsection{Agreeableness type}

Agreeableness is a personality trait that holds people to be accommodating and help (Burch and Anderson, 2008) them solve issues by creating win-win situation by their flexible attitude (Cattell and Mead, 2008). These people are usually very social (Mount et al., 2005) and friendly, generous in negotiations, usually balancing reports in tense situations. These people have a tendency to attain cooperation and social harmony (Goldberg, 1992). Helping the others is their incorporated attribute and therefore they believe that the others are also honest and trustworthy (Saucier and Goldberg, 1998). On the other hand, people who rank low in this trait of personality have a tendency to be selfish, unfriendly (Howard et al., Howard, 1995), and rough in social relationships (Ostendorf et al., 1992). For the reason that they are selfish, they believe that 
others work against them, and therefore are suspicious (Goldberg, 1992). Furthermore, these people are not concerned for the other and it is less likely they will help others by sacrificing their own interests. In the five factor personality model, only artistic, social and entrepreneurial interests were clearly related to the personality traits. Artistic interest is positively associated to agreeableness and intellect ( $r=.26$ and $r=.27$ respectively); social interest was moderately associated to agreeableness ( $r=.43)$.

\subsection{Basic personal values}

The notion value refers to beliefs on which situations or actions are desirable. Basic personal values are treated based on Salom Shwartz theory i.e. the Theory of basic values $(1994,2012)$. Shwartz perceives values as consistent standards based on which we value everything else, including the appropriateness of norms, attitudes, traits or virtues that might be suggested to us.

The values included in this study are: conformity, tradition, benevolence, universalism, self-direction, stimulation, hedonism, achievement, power and security.

1) Conformity is defined as a restraint of actions, inclinations, and impulses likely to disturb or harm others and violate social expectations or norms.

2) Tradition refers to respect, dedication, and acceptance of the customs and ideas that traditional culture or religion offer.

3) Benevolence: protection and enhancement of the people's welfare with whom the individual is in frequent personal contact

4) Universalism represents the understanding, appreciation, tolerance, and protection for the welfare of all people and for nature.

5) Self-direction: independent thought and action-choosing, creating, exploring.

6) Stimulation refers to excitement, novelty, and challenge in life

7) Hedonism: enjoyment and profound gratification for oneself.

8) Achievement: personal success through demonstrating aptitude according to social standards

9) Power refers to the inclination for social status and prestige, control or dominance over people and resources.

10) Security is defined as safety, harmony, and stability of society, of relationships, and of self.

Guth et.al (1965) stresses that: "Values are not only closely related to personality, they are part of it, and serve as a guiding system to personality when facing solutions and alternatives, values form a very consistent personality trait of an individual, especially if some values are clearly dominated by the others".

Agreeableness predicts values associated to the quality of social interaction such as: appreciating teamwork and unity and disapproval of competition and benefits. The agreeableness dimension branches the differences between the peopleoriented and objective-oriented values (McCrae and Costa, 1996).

\section{Research methodology}

The aim of this research study is to determine the level of association between the agreeableness type of personality and basic personal values through non-experimental quantitative methodology using original measuring instruments appropriate to the main variables. The set hypotheses, based on the theoretical frame, are that:

-there is positive association between the agreeableness type of personality and basic personal values.

-the agreeableness type reaches the highest level of mean score by the value universalism

The population of this research consists of all senior students of Albanian high schools in Skopje, Republic of Macedonia, (High schools: "Zef Lush Marku", "Arseni Jovkov", "Cvetan Dimov", "Pançe Karagjozov", "Vlado Tasevski", "Marija Kiri", "8 Shtatori", "Zdravko Cvetkovski"), and the total number of subjects is 479 . During the data analysis 50 subjects were 
excluded from the final results since the validity of the data was threatened. Based on gender, 200 male and 279 female subjects were included, whereas 222 lived in rural areas and 257 in urban areas. Other descriptive data was not calculated as it was not within the scope of the study goals but were set to control any factors that might threaten the results. The descriptive data present in the measuring instruments did not indicate any threats during the variable measurements. The subjects in the survey were randomly selected and their willingness to participate as well as their anonymity was fully respected by following all ethical norms.

The survey was conducted during March-April 2017 and the study as a whole ended in 30.08.2017.

\subsection{Measuring instruments}

The measurement of the variable of agreeableness type of personality was achieved through the five factor questionnaire of personality - Big Five Inventory ((BFl; John, Donahue et al, 1991 and John et al 2008)) and only the data of the items $26,27,28,29,30,31,32,33$, were processed since they obtained the sincere opinion of the subject on how much they trust others, how much they oppose others, how easy they adapt, how much they think of themselves, how concerned they are about the others and to what extent they pressure others to complete an activity.

The BFI reliability value for extraversion in Alpha Cronbach scale reached satisfactory value of .508 . The approval of nine items with the highest possible value in the answers from 1 (never) to 5 (very often) indicates that the subject has a more expressed agreeableness personality. This questionnaire is applied for the first time in Macedonia and is translated into Albanian through back translation procedure.

In previous research where this instrument is applied (Benet-Martinez and John, 1998; John et al.,2008; Soto, John, Golsing and Potter, 2008) according to Alpha Cronbach scale, it resulted with high reliability from .81 to .88 with an average .85 .

\section{The personal values questionnaire Portrait Values Questionnaire (PVQ)}

(PVQ-40; Schwartz, 2003; Schwartz et al, 2001). This questionnaire is created by SVS (Shwartz Value Survey, 1992) with the idea of developing an instrument which is less abstract. It consists of 40 items which include descriptions of individuals that support certain values, including three to six items per value. The subjects answer on the scale from 1 (very much like me) to 6 (not like me at all) to describe to what extent they comply with the value descriptions. The questionnaire is constructed to measure ten basic personal values: conformity, tradition, benevolence, universalism, self-direction, stimulation, hedonism, achievement, power and security. The portraying is achieved by two types of questions: the first one refers to the importance (it is important for them to have in their life...), and the second one refers to aspirations or desires (he/she want, seeks, believes...). The instrument resulted in high reliability on all value categories, with an exception (tradition) conformity $=.73$, benevolence $=.65$ tradition $=.51$, universalism $=.85$, self-direction $=.89$, stimulation $=78$, hedonism $=.81$, achievement $=.84$, power $=.69$ and security $=.64$ according to Carson J. Sandy, Samuel D. Gosling, Shalom H. Schwartz \& Tim Koelkebeck (2016).

The same questionnaire is used by Desirée Knoppen; Willem Sari (2009), Alvaro Tamayo, Juliana Barreiros Porto (2009), Constanze Beierlein, Eldad Davidov, Peter Schmidt, Shalom H. Schwartz, Beatrice Rammstedt (2012).

\subsection{Findings}

Table 1 presents the descriptive statistical analysis for the main variables of the study, the agreeableness type of personality and basic personal values according to the Kurtosis statistic. The agreeableness personality type is averaged $(M=20.42)$ from minimum 13 and maximum 34 and standard deviation $(S D=3.71)$. The value conformity is averaged $(M=17.53)$ from minimum 7 and maximum 24 and standard deviation $(S D=3.23)$. The value tradition is averaged $(M=17,28)$ from minimum 8 and maximum 24 and standard deviation $(S D=3,30)$, benevolence is averaged $(M=18,32)$ from minimum 7 and maximum 24 and standard deviation $(S D=3,73)$, universalism is averaged $(M=27,08)$ from minimum 13 and maximum 36 and standard deviation $(S D=5,04)$, self-direction is averaged $(M=17,83)$ from minimum 7 and maximum 24 and standard deviation $(S D=3,72)$, stimulation is averaged $(M=13,17)$ from minimum 5 and maximum 18 and standard deviation( $S D=3,03)$, hedonism is averaged $(M=12,08)$ from minimum 4 and maximum 18 and standard deviation $(S D=2,98)$, achievement is averaged $(M=17,12)$ from minimum 6 and maximum 24 and standard deviation $(S D=3,72)$, power is averaged $(M=10,13)$ from minimum 3 and maximum 18 and standard deviation $(S D=21,75)$, security is averaged $(M=21,75)$ from minimum 11 and maximum 30 and standard deviation $(S D=4,11)$. From the data it is obvious that, in contrast to other 
personal values, the dominating basic personal value of the subjects is universalism with the highest mean score from the general data.

Table 1. General mean score of agreeableness personality type and the basic personal values.

\begin{tabular}{|l|l|l|l|l|l|l|l|}
\hline & N & Minimum & Maximum & Mean & \multicolumn{2}{|l|}{ Std. Deviation } & \multicolumn{1}{|l|}{ Kurtosis } \\
\cline { 2 - 8 } & Statistic & Statistic & Statistic & Statistic & Statistic & Statistic & Std. Error \\
\hline agreeable_elimination & 479 & 13.00 & 34.00 & 23.5136 & 3.71800 & -.135 & .223 \\
PV_security & 479 & 11.00 & 30.00 & 21.7537 & 4.11877 & -.665 & .223 \\
PV_conformity & 479 & 7.00 & 24.00 & 17.5324 & 3.23140 & -.258 & .223 \\
PV_tradition & 479 & 8.00 & 24.00 & 17.2881 & 3.30216 & -.273 & .223 \\
PV_benevolence & 479 & 7.00 & 24.00 & 18.3236 & 3.73069 & -.339 & .223 \\
PV_universalism & 479 & 13.00 & 36.00 & 27.0877 & 5.04630 & -.615 & .223 \\
PV_self-direction & 479 & 7.00 & 24.00 & 17.8351 & 3.72147 & -.408 & .223 \\
PV_stimulation & 479 & 5.00 & 18.00 & 13.1795 & 3.03348 & -.381 & .223 \\
PV_hedonism & 479 & 4.00 & 18.00 & 12.0814 & 2.98105 & -.384 & .223 \\
PV_achievement & 479 & 6.00 & 24.00 & 17.1211 & 3.72737 & -.409 & .223 \\
PV_power & 479 & 3.00 & 18.00 & 10.1399 & 3.45794 & -.590 & .223 \\
Valid N (listwise) & 479 & & & & & & \\
\hline
\end{tabular}

The results presented in table 2 and 3 show the association between the agreeableness personality type and basic personal values which verify the first hypothesis stating that: there is positive association between the agreeableness and basic personal values. The data indicates that the agreeableness type has statistically significant and positive association to all basic personal values, and the association to values is as follows: conformity $(r=, 135 ; p<.01)$, tradition $(r=.122 ; p<.01)$, benevolence $(r=.249 ; p<.01)$, universalism $(r=.255 ; p<.01)$, self-direction $(r=.224 ; p<.01)$, stimulation $(r=.234 ; p<.01)$, hedonism ( $r=.274 ; p<.01)$, achievement $(r=.172 ; p<.01)$, power $(r=.119 ; p<.01)$, security $(r=173 ; p<.01)$.

Table 2. Correlations of agreeableness type of personality and basic personal values.

\begin{tabular}{|l|l|l|l|l|l|l|}
\hline & $\begin{array}{l}\text { Agreeablenes } \\
\text { s type }\end{array}$ & $\begin{array}{l}\text { Conformit } \\
\mathrm{y}\end{array}$ & $\begin{array}{l}\text { Traditio } \\
\mathrm{n}\end{array}$ & $\begin{array}{l}\text { Benevolenc } \\
\mathrm{e}\end{array}$ & $\begin{array}{l}\text { Universalis } \\
\mathrm{m}\end{array}$ & $\begin{array}{l}\text { Self- } \\
\text { direction }\end{array}$ \\
\hline $\begin{array}{cl}\text { Agreeablenes Pearson } \\
\text { s type } \begin{array}{l}\text { Correlatio } \\
\mathrm{n}\end{array}\end{array}$ & 1 & $.135^{* *}$ & $.122^{* *}$ & $.249^{* *}$ & $.255^{* *}$ & $.224^{* *}$ \\
$\begin{array}{c}\text { Sig. (2- } \\
\text { tailed) }\end{array}$ & & .003 & .007 & .000 & .000 & .000 \\
$\mathrm{~N}$ & 479 & 479 & 479 & 479 & 479 & 479 \\
\hline
\end{tabular}

**. Correlation is significant at the 0.01 level ( 2 tailed).

Table 3. Correlations of agreeableness type of personality and basic personal values.

\begin{tabular}{|c|c|c|c|c|c|c|c|}
\hline & & $\begin{array}{l}\text { Agreeablenes } \\
\text { s type }\end{array}$ & $\begin{array}{l}\text { Stimulatio } \\
n\end{array}$ & $\begin{array}{l}\text { Hedonis } \\
\text { m }\end{array}$ & $\begin{array}{l}\text { Achieveme } \\
\text { nt }\end{array}$ & $\begin{array}{l}\text { Powe } \\
r\end{array}$ & Secutiry \\
\hline \multirow[t]{3}{*}{$\begin{array}{l}\text { Agreeablenes } \\
\text { s type }\end{array}$} & $\begin{array}{l}\text { Pearson } \\
\text { Correlation }\end{array}$ & 1 & $.234^{\star *}$ & $.274^{\star *}$ & $.172^{\star *}$ & $.119^{*}$ & \\
\hline & Sig. (2-tailed) & & .000 & .000 & .000 & .009 & .000 \\
\hline & $\mathrm{N}$ & 479 & 479 & 479 & 479 & 479 & 479 \\
\hline
\end{tabular}

**. Correlation is significant at the 0.01 level (2-

tailed).

The table 4 shows the results of one way ANOVA regarding the differences of basic personal values mean scores and the agreeableness type of personality. According to the results it is proved that: the agreeableness type achieves high level on 
PV benevolence with $M=19,2763$ and $S D=3,75614$, in contrast to the average type with $M=18,4892$ and $S D=3,39729$ and the less agreeableness type with $M=17,4309$ and $S D=3,75599$ [ $F(10,910) p<.000]$. For the basic personal value universalism, the agreeableness type achieves high level $M=28,6382$ and $S D=4,43279$, in contrast to the average type with $M=26,7698$ and $S D=4,90684$ and the less agreeableness type with $M=26,0691$ and $S D=5,32781[F(11,789) p<.000]$. For the basic personal value hedonism, the agreeableness type achieves high level $M=13,2566$ and $S D=2,85290$, in contrast to the average type with $M=11,7698$ and $S D=2,75396$ and the less agreeableness type with $M=11,3617$ and $S D=2,97171[F(8,739) p<.000]$. However, there were no differences between the levels of basic personal values and the agreeableness type regarding the values: conformity, tradition, self-direction, stimulation, achievement, power and security therefore their results were not indicated in the study.

Table 4. Differences of basic personal values in the agreeableness type of personality

\begin{tabular}{|c|c|c|c|c|c|c|c|c|c|}
\hline & & $\mathrm{N}$ & Mean & Std. Deviation & Std. Error & Minimum & Maximum & $\mathrm{F}$ & Sig. \\
\hline Benevolence & $\begin{array}{l}\text { Low } \\
\text { Average } \\
\text { High } \\
\text { Total }\end{array}$ & $\begin{array}{l}188 \\
139 \\
152 \\
479\end{array}$ & $\begin{array}{l}17,4309 \\
18,4892 \\
19,2763 \\
18,3236\end{array}$ & $\begin{array}{l}3,75599 \\
3,39729 \\
3,75614 \\
3,73069\end{array}$ & $\begin{array}{l}, 27393 \\
, 28815 \\
, 30466 \\
, 17046\end{array}$ & $\begin{array}{l}7,00 \\
8,00 \\
7,00 \\
7,00\end{array}$ & $\begin{array}{l}24,00 \\
24,00 \\
24,00 \\
24,00\end{array}$ & 10,910 &, 000 \\
\hline Universalism & $\begin{array}{l}\text { Low } \\
\text { Average } \\
\text { High } \\
\text { Total }\end{array}$ & $\begin{array}{l}188 \\
139 \\
152 \\
479\end{array}$ & $\begin{array}{l}26,0691 \\
26,7698 \\
28,6382 \\
27,0877\end{array}$ & $\begin{array}{l}5,32781 \\
4,90684 \\
4,43279 \\
5,04630\end{array}$ & ,31619 & $\begin{array}{l}13,00 \\
14,00 \\
17,00 \\
13,00\end{array}$ & $\begin{array}{l}36,00 \\
36,00 \\
36,00 \\
36,00\end{array}$ & 11,789 &, 000 \\
\hline Hedonism & $\begin{array}{l}\text { Low } \\
\text { Average } \\
\text { High } \\
\text { Total }\end{array}$ & $\begin{array}{l}188 \\
139\end{array}$ & $\begin{array}{l}11,3617 \\
11,7698 \\
13,2566 \\
12,0814\end{array}$ & $\begin{array}{l}2,97171 \\
2,75396 \\
2,85290 \\
2,98105\end{array}$ & $\begin{array}{l}, 21673 \\
, 23359 \\
, 23140 \\
, 13621\end{array}$ & $\begin{array}{l}4,00 \\
5,00 \\
5,00 \\
4,00\end{array}$ & $\begin{array}{l}18,00 \\
18,00 \\
18,00 \\
18,00\end{array}$ & 19,442 &, 000 \\
\hline
\end{tabular}

The effect of agreeableness type on basic personal values stimulation and hedonism was examined through Eta square where the findings indicate as follows: the agreeableness type has a low effect on the value stimulation $(\eta 2=.112)$ or $11.2 \%$, as well as on the value hedonism ( $\eta 2=.138$ ) or $13.8 \%$., (Table 5). 
Table 5. The effect of agreeableness type on basic personal values according to Eta square.

\begin{tabular}{|l|l|l|}
\hline & Eta & Eta Squared \\
\hline Stimulation * & .335 & .112 \\
Agreeableness type & .371 & .138 \\
Hedonism * & & \\
\hline Agreeableness type & .35 \\
\hline
\end{tabular}

\section{Conclusion}

Referring to the reliable statistical results of the study which were obtained through questionnaire measurements appropriate to the main variables of the study, it was proved the agreeableness type of personality has a positive association and statistically significant to all basic personal values. These findings are not found in any previous research in the Republic of Macedonia, yet the other research show that: "Values are not only closely related to personality, they are part of it, and serve as a guiding system by personality when facing choices and alternatives, values form a very consistent personality trait of an individual, especially if some values are clearly dominated by the others" Guth et al. (1965), just as the McCrae and Costa, 1996 study shows that agreeableness predicts the values related to quality of social interaction such as: appreciating teamwork and unity and disapproval of competition and benefits.

In the five factor personality model, only artistic, social and entrepreneurial interests were clearly related to the personality traits. Artistic interest is positively associated to agreeableness and intellect ( $r=.26$ and $r=.27$ respectively); social interest was moderately associated to agreeableness ( $r=.43)$.

One way ANOVA statistical data prove that there are statistically significant differences in basic personal values in the agreeableness type of personality where the value universalism achieved the highest mean score and hedonism the lowest, whereas values such as: conformity, tradition, self-direction, stimulation, achievements, power and security had no significant differences. Other studies on the same variables show that: the agreeableness dimension branches the differences between the people-oriented and objective-oriented values (McCrae and Costa, 1996).

The effect of agreeableness type on basic personal values was examined through Eta square where the findings show that there was effect on values stimulation and hedonism ( $\eta 2=.112)$,

$(\eta 2=.138)$. These results have not been examined in any other previous research in our country and they represent a valuable and important finding in the organizational psychology which leads to opening a new chapter for further studies and researchers on the same topic.

\section{References}

[1] Alvaro Tamayo, Juliana Barreiros Porto (2009). Validity of the Portrait Values Questionnaire (PVQ) in Brazil, Psicologia: Teoria e Pesquisa Jul-Set 2009, Vol. 25 n. 3, pp. 369-376

[2] Burch G St. J, Neil A (2008). Personality as predictor of Work Related Behavior and Performance: Recent advances and directions for future. International Review of Indusrial and Organizational Psychology. Edited by G.P. Hodgkinson \& J. K. Ford. Vol. 23, John Wiley \& Sons Ltd

[3] Carson J. Sandy, Samuel D. Gosling, Shalom H. Schwartz \& Tim Koelkebeck (2016): The Development and Validation of Brief and Ultrabrief Measures of Values, Journal of Personality Assessment, DOI: 10.1080/00223891.2016.1231115

[4] Cattell HEP, Alan DM (2008). The Sage Handbook of Personality Theory Assessment, pp. 135-159.

[5] Christopher J. Soto, Oliver P. John (2008) Ten facet scales for the Big Five Inventory: Convergence with NEO $\mathrm{PI}-\mathrm{R}$ facets, self-peer agreement, and discriminant validity 
[6] Constanze Beierlein, Eldad Davidov, Peter Schmidt, Shalom H. Schwartz, Beatrice Rammstedt (2012). Testing the discriminant validity of Schëartz' Portrait Value Questionnaire items - A replication and extension of Knoppen and Saris, Survey Research Methods 6(1):25-36 ·January 2012 DOI: 10.5167/uzh-63005

[7] Desirée Knoppen; Willem Saris (2009). Evaluation of the Portrait Values Questionnaire using SEM: A New ESS Proposal, Italy, June 11-12, 2009

[8] Goldberg, LR (1993), 'The structure of phenotypic personality traits', American Psychologist, vol. 48, pp. 26-34.

[9] Guth, W. D. and R. Tagiuri. 1965. 'Personal Values and Corporate Strategy.' Harvard Business Review 43(5):123-32

[10] John, O. P., Donahue, E. M., \& Kentle, R. L. (1991). The Big Five Inventory-Versions 4a and 54. Berkeley, CA: University of California, Berkeley, Institute of Personality and Social Research.

[11] Ostendorf F, Angleitner A (1992). on the generality and comprehensiveness of the five factor model of personality : evidence for five robust factors in questionnaire data. Modern personality psychology, eds. GianVittorio Caprara et al., New York [u.a.]: Harvester Wheatsheaf, pp. 73-109.

[12] Sagiv, L., \& Schwartz, S. H. (1995). Value priorities and readiness for out-group social contact. Journal of Personality and Social Psychology, 69, 437-448.

[13] Winter, D. G., John, O. P., Stewart, A. J., Klohnen, E. C., \& Duncan, L. E. (1998). Traits and motives: Toward an integration of two traditions in personality research. Psychological Review, 105, 230-250. 